\title{
Evaluation of a screening technique for manganese toxicity in relation to leaf mangenese distribution and interaction with silicon
}

\author{
C. R. Blatt* and A. van Diest
}

Department of Soil Science and Plant Nutrition, Agricultural University, Wageningen, the Netherlands

Accepted: 22 September 1981

Key-words: lettuce, manganese toxicity, silicon

\section{Summary}

A manganese screening technique utilizing a flowing nutrient culture was used for the evaluation of 20 lettuce cultivars having a range of manganese toxicity ratings. Plant growth, leaf and root manganese and toxicity ratings were recorded over six manganese and two silicon levels. Total manganese in lettuce tops was not a useful index for manganese sensitivity. Increasing silicon resulted in a repression of manganese toxicity symptoms and decreased shoot/root ratios in twelve cultivars. A screening solution without silicon appeared to offer optimum conditions for manganese toxicity symptom development.

\section{Introduction}

The lettuce grown in steam-sterilized soil under glasshouse conditions may exhibit manganese toxicity symptoms of marginal yellowing or necrosis in older leaves. This condition is caused by a surplus of exchangeable manganese and results in unmarketable produce. The development of manganese toxicity symptoms is strongly influenced by cultivar and to a lesser extent by soil and weather conditions. Lettuce cultivars tolerant of a surplus of exchangeable manganese because of a number of genes for insensitivity are useful germ plasm and would be suitable as insensitive progenitors in a lettuce breeding program (Eenink \& Garretsen, 1977). The current method for evaluating manganese tolerance of new lettuce selections in the Netherlands involves growing plants in a steam-sterilized clay soil only during the fall months under glasshouse conditions. Lettuce studies under steam-sterilized glasshouse conditions (Sonneveld \& Voogt, $1973 \&$ 1975) and in sand culture (Messing, 1965) have demonstrated wide within-cultivar variations in susceptibility to manganese toxicity, and Foy (1976) has pointed out the importance of evaluating soil con-

* Studies performed while C. Roger Blatt, plant physiologist, was on a work transfer from Agriculture Canada Research Station at Kentville, Nova Scotia, BJN 174, Canada. Contribution No 1730. 
ditions when attempting to screen various genotypes for aluminum or manganese tolerance.

The manganese silicon interaction in Gramineae has been studied by Vlamis \& Williams (1967) and Williams \& Vlamis (1957) and results show a repression of $\mathrm{Mn}$ toxicity symptoms in the presence of silicon. Studies with barley (Williams \& Vlamis, 1957) and beans (Horst \& Marschner, 1978) using radioactive $\mathrm{Mn}$ in the presence and absence of silicon indicate that silicon alters the distribution of $\mathrm{Mn}$ in the leaf tissue thus preventing points of accumulation that ultimately give rise to necrotic spots. The studies with the Gramineae indicated that silicon had little or no effect on Mn content of leaf tissue and that in some crops silicon increased yield.

The present study was undertaken in an attempt to develop a screening technique that would be consistent and rapid in its evaluation of large numbers of lettuce selections for manganese tolerance. In addition, a manganesesilicon interaction and the distribution of manganese in leaves of various ages were studied.

\section{Materials and methods}

\section{Screening trials}

Four experiments were conducted with lettuce seedlings that were grown for 21-28 days from seeding in a glasshouse potting mix prior to being transferred to 60 -litre tanks and a flowing nutrient culture. Nutrients were supplied by a $20 \%$ Hoagland's solution No l at pH 5.5 with modified micronutrients (Vlamis \& Williams, 1962) and iron supplied as Fe-EDTA at $0.5 \mathrm{mg} / \mathrm{l} \mathrm{Fe}$. Twelve cultivars with six seedlings per cultivar were grown in each tank and there were four tanks with one manganese concentration per tank in each experiment. Solutions were renewed once or twice weekly depending on plant size. Experiments were conducted in controlled environment chambers with ten hours of light at 17000-20000 lux intensity and each was 4-5 weeks duration. Three experiments utilized a constant temperature of $17^{\circ} \mathrm{C}$ and one experiment operated with $30^{\circ} \mathrm{C}$ day and $17^{\circ} \mathrm{C}$ night. A total of 20 lettuce (Lactuca sativa L.) cultivars (Ardente, Avoncrisp, Deci-minor, Deciso, Hilde, Kloek, Minetto, Neptune, Noran, Ostinata, Plenos, Plus, Proeftuin Blackpool, Rapide, Ravel, Renate, Solito, Troppo, Vitesse, Wonder van Voorburg), each with a relative position on a toxicity scale of $1-10$ or $1-5$ (no to high toxicity), under glasshouse conditions, were evaluated at Mn levels of $0.1,0.25,0.5,1.0,2.0$ and $4.0 \mathrm{mg} / \mathrm{l}$. A cultivars' rating on the toxicity scale was related to the severity of marginal yellowing or necrosis in older leaves and how the symptoms affected growth.

\section{Manganese-silicon interaction}

A manganese-silicon interaction was studied in an experiment involving twelve cultivars, a constant $\mathrm{Mn}$ level of $0.5 \mathrm{mg} /$ litre and silicon levels of $0,0.5 \mathrm{and}$ $1.5 \mathrm{mmol} \mathrm{Si} /$ litre (sodium silicate solutions adjusted to $\mathrm{pH} 5.5$ with $\mathrm{HCl}$ ). Seedling age, basic nutrient solution, environmental conditions with constant 
$17^{\circ} \mathrm{C}$ and experiment duration were as previously described. Three tanks were used and each tank contained one level of silicon.

\section{Change in leaf $M n$ distribution with age}

Seedlings of the Mn-tolerant cultivar Plenos and the Mn-sensitive Proeftuin Blackpool were grown in a flowing nutrient culture experiment, without $\mathrm{Si}$, at a $\mathrm{Mn}$ level of $0.5 \mathrm{mg} /$ litre with plants harvested each week for four weeks. Two tanks were used with one cultivar per tank. Leaves were separated into four age categories from the exterior to interior of the plant and designated as old, mid, young and heart with the heart leaves being further divided into three or four age groups where applicable. Young leaves were categorized as those adjacent to but not part of the heart cluster of leaves.

\section{Tissue analysis}

Roots were submerged in $0.01 \mathrm{~N} \mathrm{HCl}$ for $5-10 \mathrm{~min}$ and rinsed in tap water prior to fresh weight measurements. Leaf and root samples were weighed fresh at harvest, dried at $70^{\circ} \mathrm{C}$, reweighed for dry weights and ground in a coffee mill. Samples were wet ashed with either $\mathrm{H}_{2} \mathrm{SO}_{4}-\mathrm{H}_{2} \mathrm{O}_{2}$ or $\mathrm{HNO}_{3}-\mathrm{HClO}_{4}-$ $\mathrm{H}_{2} \mathrm{SO}_{4}$ digestion mixtures prior to the determination of $\mathrm{Mn}$ by atomic absorption spectrophotometry.

\section{Results}

\section{Screening trials}

Utilizing the flowing culture technique, a Mn level of either 0.5 or $1.0 \mathrm{mg} /$ litre produced $\mathrm{Mn}$ toxicity ratings that were consistent within each cultivar over the three experiments conducted at a constant $17^{\circ} \mathrm{C}$. In these experiments, the rate of development of toxicity symptoms was dependent on each cultivar's sensitivity. Some cultivars exhibited marginal necrosis of old leaves and dark spots on younger leaves within seven to ten days after transfer to the screening solution. Other, less sensitive cultivars took three to four weeks before leaf spotting (Williams \& Vlamis, 1957) or marginal chlorosis of oldest leaves (Vlamis \& Williams, 1973) became evident. Tolerant cultivars exhibited no symptoms. Total time involved was seven to eight weeks from seed sowing to evaluation of cultivars for $\mathrm{Mn}$ sensitivity. In a fourth experiment, raising day temperatures to $30^{\circ} \mathrm{C}$ and maintaining a $17^{\circ} \mathrm{C}$ night at a light intensity similar to previous experiments reduced the $\mathrm{Mn}$ concentration required to show toxicity, and ratings at $0.1 \mathrm{mg} /$ litre $\mathrm{Mn}$ were similar to those at $0.5 \mathrm{mg} /$ litre $\mathrm{Mn}$ in the previous experiments. Under these temperature conditions $\left(30^{\circ} / 17^{\circ} \mathrm{C}\right)$ and a Mn level of $0.5 \mathrm{mg} /$ litre the toxicity rating in seven of twelve cultivars was changed (Table 1).

Leaf and root $\mathrm{Mn}(\mu \mathrm{g} / \mathrm{plant})$ variability was similar to that found by Sonneveld \& Voogt (1975) with no correlation between plant accumulation of $\mathrm{Mn}$ and cultivar tolerance. There was a trend for leaf and root $\mathrm{Mn}$ to increase with 


\section{R. BLATT AND A, VAN DIEST}

Table 1. The effect of day temperature on manganese toxicity rating* in 12 lettuce cultivars grown in solution culture containing $0.5 \mathrm{mg} /$ litre $\mathrm{Mn}$.

\begin{tabular}{lll}
\hline Cultivar & \multicolumn{2}{l}{ Temperature (day/night) } \\
\cline { 2 - 3 } & $17^{\circ} \mathrm{C} / 17^{\circ} \mathrm{C}^{* *}$ & $30^{\circ} \mathrm{C} / 17^{\circ} \mathrm{C}^{* * *}$ \\
Plenos & 1 & 4 \\
Plus & 1 & 1 \\
Ravel & 1 & 4 \\
Deci-minor & 2 & 3 \\
Ostinata & 3 & 5 \\
Rapide & 3 & 5 \\
Deciso & 4 & 5 \\
Hilde & 4 & 4 \\
Noran & 4 & 4 \\
Renate & 4 & 5 \\
Proeftuin Blackpool & 5 & 5 \\
Solito & 5 & 5
\end{tabular}

* Toxicity rating: $1=$ no toxicity. $5=$ highest toxicity.

** Seedlings were 28 days old when transferred to screening solution and toxicity was rated 28 days later at harvest.

*** Seedlings were 28 days old when transferred to screening solution and toxicity was rated 32 days later at harvest.

Table 2. The effect of increasing silicon on manganese toxicity rating* in 12 lettuce cultivars grown in solution culture at $0.5 \mathrm{mg} /$ litre $\mathrm{Mn}$.

Cultivar

Si level (mmol/litre)

$\overline{0} \overline{0.5} \overline{1.5}$

$\begin{array}{lll}1 & 1 & 1 \\ 1 & 1 & 1 \\ 1 & 1 & 1 \\ 2 & 1 & 1 \\ 3 & 1 & 1 \\ 3 & 2 & 1 \\ 4 & 2 & 1 \\ 4 & 2 & 1 \\ 4 & 2 & 2 \\ 4 & 2 & 3 \\ 5 & 4 & 2 \\ 5 & 2 & \end{array}$

* Toxicity rating: $1=$ no toxicity, $5=$ highest toxicity.

** Seedlings were 28 days old when transferred to screening solution and toxicity was rated 28 days later at harvest. 
increasing $\mathrm{Mn}$ in solution and a $30^{\circ} \mathrm{C}$ day had a tendency to increase plant $\mathrm{Mn}$ at all solution $\mathrm{Mn}$ levels.

\section{Manganese-silicon interaction}

Increasing silicon in solution changed toxicity ratings (Table 2) for the majority of the cultivars, with the $0.5 \mathrm{mmol} \mathrm{Si} /$ litre $(14 \mathrm{mg} /$ litre) level giving the most substantial response. Leaf $\mathrm{Mn}(\mu \mathrm{g} / \mathrm{plant})$ and leaf dry weight $(\mathrm{mg} / \mathrm{plant})$ decreased in nine of twelve cultivars and shoot/root ratio decreased in all cultivars as silicon increased from 0-1.5 mmol (Table 3). Proeftuin Blackpool was an exception having exhibited a marked increase in leaf $\mathrm{Mn}$ and dry weight. Root Mn and dry weight increased in the majority of cultivars and there were root dry weight increases in one of the three tolerant, two of the three intermediate and all of the sensitive cultivars with increasing silicon.

\section{Change in leaf $M n$ distribution with age}

Leaf Mn ( $\mu \mathrm{g} /$ plant) values for Plenos were higher than those for Proeftuin Blackpool at all leaf ages and sampling dates in solution culture. Leaf $\mu \mathrm{g}$ $\mathrm{Mn} / \mathrm{mg}$ dry matter values were higher in the old leaves $(\mathrm{O})$ of Plenos compared with those of Blackpool and leaf $\mathrm{Mn}$ increased in old leaves of both cultivars from week one to week four (Fig. 1). Midleaf (M) accumulation of Mn for Plenos increased to the 3rd sampling date and then declined, while Blackpool midleaf values increased steadily over the four-week sampling period. Manga-

Table 3. Shoot/root (S/R) ratios and change (\%) in leaf and root $\mathrm{Mn}(\mu \mathrm{g} / \mathrm{plant})$ and dry weight $(\mathrm{mg} / \mathrm{plant}$ ) in 12 lettuce cultivars grown in solution cultures containing $0.5 \mathrm{mg} /$ litre $\mathrm{Mn}$ and two Si levels.

\begin{tabular}{|c|c|c|c|c|c|c|c|}
\hline \multirow[t]{3}{*}{ Cultivar } & \multirow{3}{*}{$\begin{array}{l}\text { Mn rating } \\
\text { at } \\
0 \mathrm{mmol} \mathrm{Si} / \text { litre }\end{array}$} & \multicolumn{2}{|c|}{$\begin{array}{l}\mathrm{S} / \mathrm{R} \\
\mathrm{mmoles} \mathrm{Si} / \mathrm{litre}\end{array}$} & \multicolumn{4}{|c|}{$\begin{array}{l}\text { Change (\%) from } \\
0-1.5 \mathrm{mmol} \mathrm{Si} / \text { litre }\end{array}$} \\
\hline & & \multirow[t]{2}{*}{0} & \multirow[t]{2}{*}{1.5} & \multicolumn{2}{|l|}{ leaf } & \multicolumn{2}{|l|}{ root } \\
\hline & & & & $\overline{M n}$ & $\mathrm{DM}$ & $\mathrm{Mn}$ & $\mathrm{DM}$ \\
\hline Plenos** & $1^{*}$ & 10.1 & 5.2 & -33 & -27 & +41 & +43 \\
\hline Plus & 1 & 7.5 & 5.2 & -71 & -40 & -59 & -13 \\
\hline Ravel & 1 & 8.7 & 5.1 & -59 & -49 & -46 & -13 \\
\hline Deci-monor & 2 & 7.7 & 6.4 & -36 & -5 & -32 & +14 \\
\hline Ostinata & 3 & 9.0 & 7.0 & -36 & -8 & +12 & +18 \\
\hline Rapide & 3 & 7.9 & 4.0 & -87 & -70 & -67 & -40 \\
\hline Deciso & 4 & 9.0 & 3.6 & -59 & -50 & +15 & +25 \\
\hline Hilde & 4 & 7.2 & 4.6 & +23 & +23 & +41 & +91 \\
\hline Noran & 4 & 10.6 & 8.8 & -19 & +32 & +30 & +58 \\
\hline Renate & 4 & 8.5 & 6.4 & -44 & -20 & +7 & +7 \\
\hline Proeftuin Blackpool & 5 & 8.5 & 5.5 & +59 & +138 & +151 & +267 \\
\hline Solito & 5 & 9.0 & 5.8 & -29 & -17 & +11 & +29 \\
\hline
\end{tabular}

* Toxicity rating: $1=$ no toxicity, $5=$ highest toxicity.

** Seedlings were 28 days old when transferred to screening solution and toxicity was rated 28 days later at harvest. 


\section{$\mu \mathrm{g} M \mathrm{~m} / \mathrm{mg} \mathrm{DW}$}

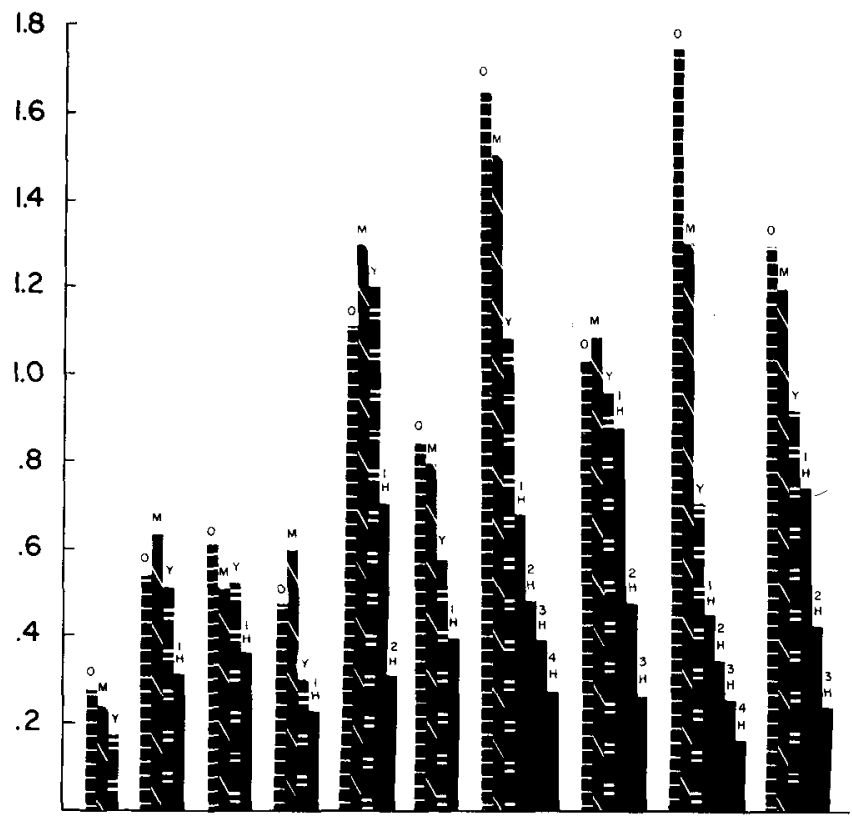

PL.Pr.BL. PL. Pr.BL. PL. Pr.BL. PL. Pr.BL. PL. Pr.BL.

POT MIX WEEK 1 WEEK 2 WEEK 3 WEEK 4

Fig. 1. $\mathrm{Mn}(\mu \mathrm{g} \mathrm{Mn} / \mathrm{mg} \mathrm{DW})$ in leaves of varying age of the lettuce cultivars Plenos (Pl.) and Proeftuin Blackpool (Pr. Bl.) grown on solution culture at $0.5 \mathrm{mg} /$ litre $\mathrm{Mn}$.

Pot mix : sample prior to transfer to solution culture.

Week 1-4: plants grown on solution culture and sampled 1-4 weeks after transfer from pot mix.

$\mathrm{O}=$ old leaves: $\mathrm{M}=$ mid leaves: $\mathrm{Y}=$ young leaves: $1 \mathrm{H}-4 \mathrm{H}=$ heart leaves (old to young).

nese levels in young $(\mathrm{Y})$ and heart $(1-4 \mathrm{H})$ leaves in Plenos were highest early in the experiment and then declined over subsequent samplings, whereas Blackpool values for the same aged leaves tended to increase over the course of the study and remained high until the end of the experiment. Blackpool values for heart $(1 \mathrm{H}$ and $2-\mathrm{H})$ and young $(\mathrm{Y})$ leaves were higher than those for Plenos at the last sampling date. A higher percentage of total Mn was retained in the old and mid leaves of Blackpool compared with Plenos over the first two sampling dates (63-68 vs. 52-56\%). This trend was reversed at the last two sampling dates with Blackpool having a lower percentage of total $\mathrm{Mn}$ in the old and mid leaves than Plenos (45-52 vs. 52-62 \%).

\section{Discussion}

\section{Screening trials}

It appears that a screening solution containing 0.5-1.0 $\mathrm{mg} /$ litre $\mathrm{Mn}$ can pro- 
duce consistent $\mathrm{Mn}$ toxicity ratings for lettuce cultivars varying in manganese tolerance. The manganese toxicity ratings in these trials for tolerant and very sensitive cultivars were similar to those ratings for these same cultivars grown under glasshouse conditions. Ratings of cultivars with intermediate toxicity symptoms tended to vary between the two screening systems. The controlled environment system produced a more consistent rating for these cultivars and one that was a more reliable indication of actual toxicity. Toxicity ratings of these intermediate cultivars under glasshouse conditions have been variable due to soil and weather conditions and since only one trial is possible per year, there is a time loss before results can be repeated.

Constant temperature $\left(17^{\circ} \mathrm{C}\right)$ was an important factor leading to consistent results. Raising the day temperature to $30^{\circ} \mathrm{C}$ at a light intensity equal to the $17^{\circ} \mathrm{C}$ day experiments produced more rapid growth, but also more severe toxicity symptoms, a result contrary to Heenan \& Carter (1977) with two soybean cultivars. Although it may seem desirable to reduce the screening trial period by raising day temperature and thus increase growth rate, lettuce is susceptible to tip-burn under these conditions and this can add an unnecessary variable to the trial.

\section{Manganese-silicon interaction}

The manganese-silicon interaction produced an initial reaction similar to that reported by Williams \& Vlamis (1957) and Vlamis \& Williams (1967); namely, a repression of $\mathrm{Mn}$ toxicity symptoms in the presence of silicon (Table 2). The majority of lettuce cultivars screened exhibited decreased leaf $\mathrm{Mn}$ and dry weight with increasing silicon while the reverse was the case with root $\mathrm{Mn}$ and dry weight (Table 3). It is interesting to note that while increasing silicon resulted in increased root dry weight in nine of twelve cultivars, only three of these cultivars showed an increase in leaf dry weight. The overall consistent effect of increasing silicon was the reduction of the shoot/root ratio, in all twelve cultivars, by as much as $50 \%$ in the case of Plenos, Rapide and Deciso. This indicates that although increasing silicon reduced toxicity symptoms, in the majority of cultivars it did not have a beneficial effect on top growth.

A screening trial conducted in solution culture without silicon provides more suitable conditions for $\mathrm{Mn}$ toxicity symptom development than trials in soil. Cultivars exhibiting only a narrow yellowing of the leaf margins of older leaves in solution culture could appear completely tolerant under glasshouse soil conditions with soluble silica present.

\section{Change in Mn leaf distribution with age}

At each of the four weekly sampling dates in the experiment referred to in Fig. 1 , total $\mathrm{Mn}$ in the leaves of Plenos (tolerant to $\mathrm{Mn}$ ) was greater than that of Blackpool (sensitive to $\mathrm{Mn}$ ), indicating that a tolerant cultivar does not restrict Mn translocation to the leaves compared with the sensitive one. However, as the experiment progressed, Blackpool tended to accumulate a higher percentage of its total Mn in the heart tissue than did Plenos indicating a greater move- 
ment or redistribution of $\mathrm{Mn}$ in Blackpool. This could account for the fact that Blackpool exhibited toxicity symptoms in old, mid, young and all but the very youngest heart tissue $(3-\mathrm{H})$ and the absence of toxicity symptoms in this tissue (3-H) was presumably due to low accumulation. Both cultivars tended to accumulate $\mathrm{Mn}$ in old and mid leaves as the experiment progressed, but only Blackpool continued to accumulate $\mathrm{Mn}$ in young and outside heart $(\mathrm{l}-\mathrm{H})$ leaves. Thus, the differences in Mn sensitivity among cultivars could possibly be attributed to variations in the ease with which $\mathrm{Mn}$ is translocated to the younger leaves. In this regard, total $\mathrm{Mn}$ in lettuce tops does not appear to be a useful index of Mn sensitivity.

\section{Acknowledgements}

The authors wish to thank A. H. Eenink and C. M. Rodenburg for supplying the lettuce seed and R. van Eck for technical assistance.

\section{References}

Eenink, A. H. \& F. Garretsen, 1977. Inheritance of insensitivity of lettuce to a surplus of exchangeable manganese in steam-sterilized soils. Euphytica 26: 47-53.

Foy, C. D. 1976. General principles involved in screening plants for aluminum and manganese tolerance. In: M. J. Wright (Ed.), Plant adaptation to mineral stress in problem soils. Cornell University, Ithaca, N. Y., pp. 361-386.

Heenan. D. P. \& O. G. Carter, 1977. Influence of temperature on the expression of manganese toxicity by two soybean varieties. Plant Soil $47: 219-227$.

Horst, W. J. \& H. Marschner, 1978. Effect of silicon on manganese tolerance of bean plants (Phaseolus vulgaris L.). Plant Soil 50: 287-303.

Messing. I. H. L., 1965. 5. Some differences in the growth of lettuce varieties at a high manganese level in sand culture. Rep. Glasshouse Crops Res. Inst. 1964, pp. 142-148.

Sonneveld, C. \& S. Voogt, 1973. The effects of soil sterilisation with steam-air mixtures on the development of some glasshouse crops. Plant Soil 38: 415-423.

Sonneveld, C. \& S. Voogt, 1975. Studies on the manganese uptake of lettuce on steam-sterilised glasshouse soils. Plant Soil 42: 49-64.

Vlamis, J. \& D. E. Williams, 1962. Ion competition in manganese uptake by barley plants. Plant Physiol. 37: 650-655.

Vlamis, J. \& D. E. Williams, 1967. Manganese and silicon interaction in the gramineae. Plant Soil 27: 131-141.

Vlamis, J. \& D. E. Williams, 1973. Manganese toxicity and marginal chlorosis of lettuce. Plant Soil 39: $245-251$.

Williams, D. E. \& J. Vlamis, 1957. Manganese toxicity in standard culture solutions. Plant Soil 8: 183-193.

Williams, D. E. \& J. Vlamis, 1957. Manganese and boron toxicities in standard culture solutions. Soil Sci. Soc. Am. Proc. 21: 205-209.

Williams, D. E. \& J. Vlamis, 1957. The effect of silicon on yield and manganese-54 uptake and distribution in the leaves of barley plants grown in culture solutions. Plant Physiol. 32: 404-409. 